\title{
Advances in multiple square wave techniques for ion-exchange voltammetry at ultratrace levels: the europium(III) case
}

\author{
Ligia M. Moretto a , Jean Chevalet ${ }^{\text {b }}$, Gian Antonio Mazzocchin a, Paolo Ugo a,* \\ ${ }^{a}$ Department of Physical Chemistry, University of Venice, S. Marta 2137, I-30123 Venice, Italy \\ ${ }^{\mathrm{b}}$ LI2C, Laboratoire d'Electrochimie, Université P. et M. Curie, UMR 7612 CNRS, boite 51, 4 place Jussieu, 75252 Paris Cedex 05, France
}

Received 30 March 2000; received in revised form 31 July 2000; accepted 31 July 2000

In honour of Fred Anson for his dedication to and excellence in the field of electrochemistry.

\begin{abstract}
This paper reports on the use of multiple square wave voltammetry, MSWV, for the determination of europium(III) preconcentrated by ion-exchange at glassy carbon electrodes coated with Nafion ${ }^{\circledR}$. For this aim, a double-differential (DD) mode of MSWV is implemented; with this mode, background signals are always straight lines while the analyte signal is given as a twin opposite peak system which corresponds approximately to the instrumental double differential of the classical voltammetric wave. The influence of scan parameters and experimental conditions on MSW-DD responses for europium(III) determinations at the modified electrode is examined. Detection limits and sensitivities obtained using MSW-DD are significantly superior to those achievable by classical pulsed techniques. The method is applied to the determination of ultratrace europium(III) concentrations in the $10^{-11}-10^{-10} \mathrm{M}$ range in the cooling water of a nuclear plant; results obtained by the MSW-DD ion-exchange voltammetric approach compare well with those obtained by ICP-MS. C) 2001 Elsevier Science B.V. All rights reserved.
\end{abstract}

Keywords: Nafion ${ }^{\circledR}$; Europium; Ultratrace analysis; Multiple pulse; Ion-exchange; Voltammetry

\section{Introduction}

With the continuing effort of developing more sensitive electroanalytical methods suitable for ultratrace analysis, new possibilities have been opened up by the use of electrodic systems able to preconcentrate and detect selectively low concentrations of the analyte, as in the case of polymer coated electrodes [1,2], which have found wide electroanalytical application in a variety of fields giving rise to a new sensitive technique named ion-exchange voltammetry (IEV) [3-5]. The preconcentration capabilities of electrodes modified with coatings of ion-exchangers can be better exploited for electroanalytical purposes when coupled to new instrumental techniques able to increase the signal to noise ratio and to lower detectable concentrations even below the (good) limits already reachable by using 'classical' pulsed techniques, such as differential pulse voltamme-

\footnotetext{
* Corresponding author: Fax: + 39-041-2578594.

E-mail address: ugo@unive.it (P. Ugo).
}

try and Osteryoung's square wave voltammetry. Progress in this direction has recently come from the application of a new pulsed technique named multiple square wave voltammetry (MSWV) [6,7].

MSWV is based on the principle of repeated addition of the integrated transient currents produced after each transition of a multiple potential step sequence applied at the electrode [6,7]. MSWV is a multi-pulse technique which implies a combination of a square wave signal with a staircase waveform, the latter scanning the entire domain of electroactivity of the system under analysis. This perturbation mode is similar to Barker's square wave voltammetry $[8,9]$ with the difference that onto each step of the staircase, more than one pair of square pulses of opposing sign are applied. Proper sampling of the charge during the pulse sequence allows the improvement of the signal to noise ratio so that it is possible to achieve detection limits lower than those obtained with conventional pulsed techniques. It was shown that this technique enhances the signal to noise ratio and the sensitivity $[10,11]$ mostly because of the 
averaging effect of the repeated perturbations and of the enhanced separation of the faradic and capacitative currents. It can be successfully applied for trace analysis even in complex samples [11-14].

More recently, it was shown that multiple square wave ion-exchange voltammetry at $\mathrm{Nafion}^{\circledR}$ coated electrodes allows determination of the methylmercury cation in aqueous solutions at significantly low (nanomolar and even subnanomolar) concentration levels [15]. For this purpose, and more generally for all measurements at trace concentration levels, a new MSWV mode called double differential square wave (MSW-DD where DD is double differential) has been implemented and successfully applied.

MSW-DD performs combinations of summations and differences of the integrals of the multiple transients in correlation with the polarity of the transitions and with the inversion of the superimposed square wave signal of amplitude $\Delta E_{\mathrm{amp}}$. The response of this particular mode of MSW-DD has the shape of the first derivative of the usual mode (i.e. second derivative of the polarographic wave) and offers a further increase in the signal to noise ratio. A schematic drawing of the waveform used in MSW-DD and the response obtained for a reversible one-electron process is sketched in Fig. 1. For the reversible case, the twin peaks of opposite sign appear at potentials equal to $\left(E_{1 / 2}-\Delta E_{\text {amp }} / 2\right)$ and $\left(E_{1 / 2}+\Delta E_{\text {amp }} / 2\right)$, respectively. Note that the amplitudes of the responses are presented using the nanoampere scale, not charges as would be expected from the principles of MSWV. This comes from an instrumental procedure which calculates the average value of all the

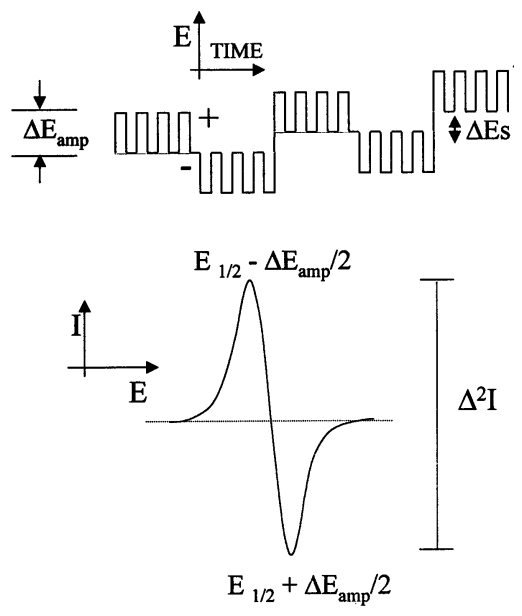

Fig. 1. Schematic drawing of the sequence of pulses and the response obtained for a MSW in the double differential mode (MSW-DD) for a reversible one-electron redox process. The sequence is reduced to $N=4$. The sum of the element of charges corresponding to the $\Delta E+$ pulses produces one component of the response; the other one comes from the $\Delta E-$ part of the signal. The final response is the sum of these two components. $\Delta E_{\mathrm{s}}$ pulse height of the staircase; $\Delta E$ pulse height ( $=\Delta E_{\mathrm{amp}}$ in the text). transient currents at each potential step of the staircase. The sum of the recorded charges is in fact normalised with respect to the sum of integration times; therefore the output is the current given by Eq. (1):

$\Delta^{2} I=1 / N \Sigma\left(Q / T_{\text {int }}\right)$

where $T_{\text {int }}$ is the integration time applied to each transient; $\Delta^{2} I$ is used to indicate that the signal corresponds really to the double derivative of $I$.

If such a normalisation were omitted, all measurements would stay numerically directly affected by the value of $N$. What is relevant from an analytical point of view is that the response $\Delta^{2} I$ is directly proportional to the concentration of the electrochemical species.

The baseline of MSW-DD becomes a flat background line at a nearly zero charge value for concentrations down to ppb level (using e.g. anodic stripping voltammetry), while in the worst cases, as in ultra trace analysis far below the ppb range, the baseline of the DD response is (close to) a sloping straight line. It is important to mention that the double level of derivation of MSW-DD is produced in real time using only specific arrangements of the transient charges, i.e. operating directly on the physical elements of the electrical response and without any subsequent mathematical treatment. This result is close to the response that would give the operation of derivation (numerical) of the baseline of the normal MSWV response which is (close to) a parabola (as well as for SWV, under similar conditions), however the added 'noise' is much less with the DD mode. The quasi-linear background component obtained by MSW-DD is then easy to subtract or to compensate for during the potential scan and this allows further improvement of the real sensitivity of the measurement.

In practice, MSW-DD acts, at a first level, on the non-faradic components of the electrochemical response, leaving a quasi-linear baseline which remains practically unchanged during a set of experiments (provided that no major modification of the electrolyte solution occurs). This allows one to obtain accurate significant determinations by a simple direct peak to peak measurement even for very low concentration applications. At another level, as well as MSWV, the DD mode performs a fast real time filtering and averaging for each data point of the voltammogram; this is due to the procedure (repeated integration, etc.) of the measurement itself. The corresponding time window (10 $\mu$ s to $100 \mathrm{~ms}$ ) is such that the main noises which may pollute the faradic component (electrochemical and mechanical fluctuations, electrical perturbations due to non-ideal signals and circuits, own noise of the closed loop potentiostatic system and current conversion amplifiers, etc.) are strongly damped.

When working with analytical methods for the determination of subnanomolar concentrations, great care 
must be taken in order to avoid artefacts coming from possible sample contamination or analyte losses caused, for instance, by adsorption of the analyte on the vessel walls or by its volatilisation. With respect to such constraints, even using all possible experimental care, methylmercury does not represent the best choice. It is in fact volatile and tends to adsorb on hydrophobic surfaces [16]. The influence of this limitation for the determination of the detection limits of MSW-DD was clearly stated in Ref. [15].

The analyte of choice for testing the level of performances of the MSWV-Nafion ${ }^{\circledR}$ coated electrode combination should be a multiple-charged cation of well known and, possibly, simple electrochemical behaviour, which is preconcentrated by $\mathrm{Nafion}^{\circledR}$ and which is not usually widespread as a possible source of contamination (at ultratrace levels) of the glassware or of the laboratory atmosphere. On the basis of this statement and on previous experience gained in our laboratory $[17,18], \mathrm{Eu}(\mathrm{III})$ was chosen as a target analyte on which to test the limit of the performance offered by the MSW-IEV approach.

It was recently shown, in fact, that europium(III) is preconcentrated efficiently at $\mathrm{Nafion}^{\circledR}$ coated electrodes [17]. At the modified electrode this rare earth cation undergoes a (quasi-)reversible one-electron reduction process and the analytical performances of the ion-exchange voltammetric determination of $\mathrm{Eu}^{3+}$ (and of ytterbium as well) are improved by using differential pulse detection of the preconcentrated analyte [18]. A detection limit of $3 \times 10^{-8} \mathrm{M}$ was obtained.

In a recent preliminary note [19], we have shown that the preconcentration capabilities of $\mathrm{Nafion}^{\circledR}$ towards $\mathrm{Eu}(\mathrm{III})$ in water solutions are superior to those of other cation exchangers such as the Eastman Kodak AQ55. It was also shown that the use of MSW-DD at Nafion ${ }^{\circledR}$ coated electrodes allows an improvement of trace europium determination, pushing the detection limit below the nanomolar concentration level.

In this paper we present the results of a study aimed at clarifying the role of the MSWV parameters on the double differential responses gained for the system under study and to optimise the method for ultratrace analysis in real samples.

It is worth pointing out that such an effort can find a variety of applications linked to the widespread interest in europium determination related to its use in many advanced technological applications [20], as well as in biological, geochemical and environmental studies $[21,22]$. With the aim of testing the relevance and the potentialities of this new technique in such fields of high interest, we present in this paper an application of the MSW-DD-IEV method to the determination of ultratrace europium in the cooling waters of a nuclear plant.

\section{Experimental}

\subsection{Chemicals and procedures}

All chemicals used were of analytical grade quality, apart from $\mathrm{NaCl}, \mathrm{HCl}$ and $\mathrm{CH}_{3} \mathrm{COONa}$ which were of Suprapur $^{\circledR}$ grade (Merck). Europium solutions were prepared by dissolving the proper amount of $\mathrm{EuCl}_{3} \cdot 6 \mathrm{H}_{2} \mathrm{O}$ (Aldrich) or using europium $1000 \mathrm{ppm}$ standard solution (Merck).

Milli-Q water was used throughout to prepare the solutions. The measurements were performed in a clean laboratory, under a Class 100 laminar flow hood. All electroanalytical measurements were carried out at room temperature $\left(22 \pm 1^{\circ} \mathrm{C}\right)$ under a nitrogen atmosphere. A conventional single compartment cell equipped with a platinum coil counter electrode and a $\mathrm{Ag}|\mathrm{AgCl}| \mathrm{KCl}_{\text {sat }}$ reference electrode were employed. The working electrode was a PTFE shrouded glassy carbon disk (area $0.2 \mathrm{~cm}^{2}$ ) polished to a mirror finish with graded alumina powder. The electrochemical cell was shielded from outer electric fields by a Faraday cage.

$2.5 \% \mathrm{w} / \mathrm{v}$ Nafion ${ }^{\circledR}$ solutions were prepared by $1: 1$ dilution with methanol of $5 \% \mathrm{w} / \mathrm{v}$ Nafion ${ }^{\circledR}$ solutions (Aldrich). Nafion ${ }^{\circledR}$ coated electrodes (NCE) were prepared by droplet evaporation of $3 \mu \mathrm{l}$ of the $2.5 \% \mathrm{w} / \mathrm{v}$ Nafion ${ }^{\circledR}$ (film coating $0.375 \mathrm{mg} \mathrm{cm}{ }^{-2}$ and film thickness of $2 \mu \mathrm{m}$, calculated using $1.58 \mathrm{~g} \mathrm{~cm}^{-3}$ as the density of the wet $\mathrm{Na}^{+}$form of Nafion ${ }^{\circledR}$ [23]).

Preconcentration of europium was carried out under open circuit conditions in stirred solutions.

Nuclear plant waters were sampled from the cooling system of a nuclear pool type reactor $\mathrm{B} \& \mathrm{~W}$ design (IEA-R1, IPEN/CNEN-SP, Brazil). The reactor pool is divided in two sections: one is the core pool (where the core and irradiation facilities are located) and the other is the spent fuel pool, where the spent fuel storage is located [24]; sampling was carried out at $4 \mathrm{~m}$ from the reactor while it was operating at a power of $5 \mathrm{MW}$. The electrochemical measurements were carried out in $10 \mathrm{ml}$ of the water sample, spiked with $0.1 \mathrm{M} \mathrm{NH}_{4} \mathrm{Cl}$ and $0.2 \mathrm{M} \mathrm{HCl}$ up to a final concentration of $10^{-3} \mathrm{M}$ and $10^{-4} \mathrm{M}$, respectively.

\subsection{Instrumentation}

Multiple square wave voltammetric experiments were carried out using a prototype instrument 'MPulse', controlled by its own software, which is currently under development for commercial production [10]. 


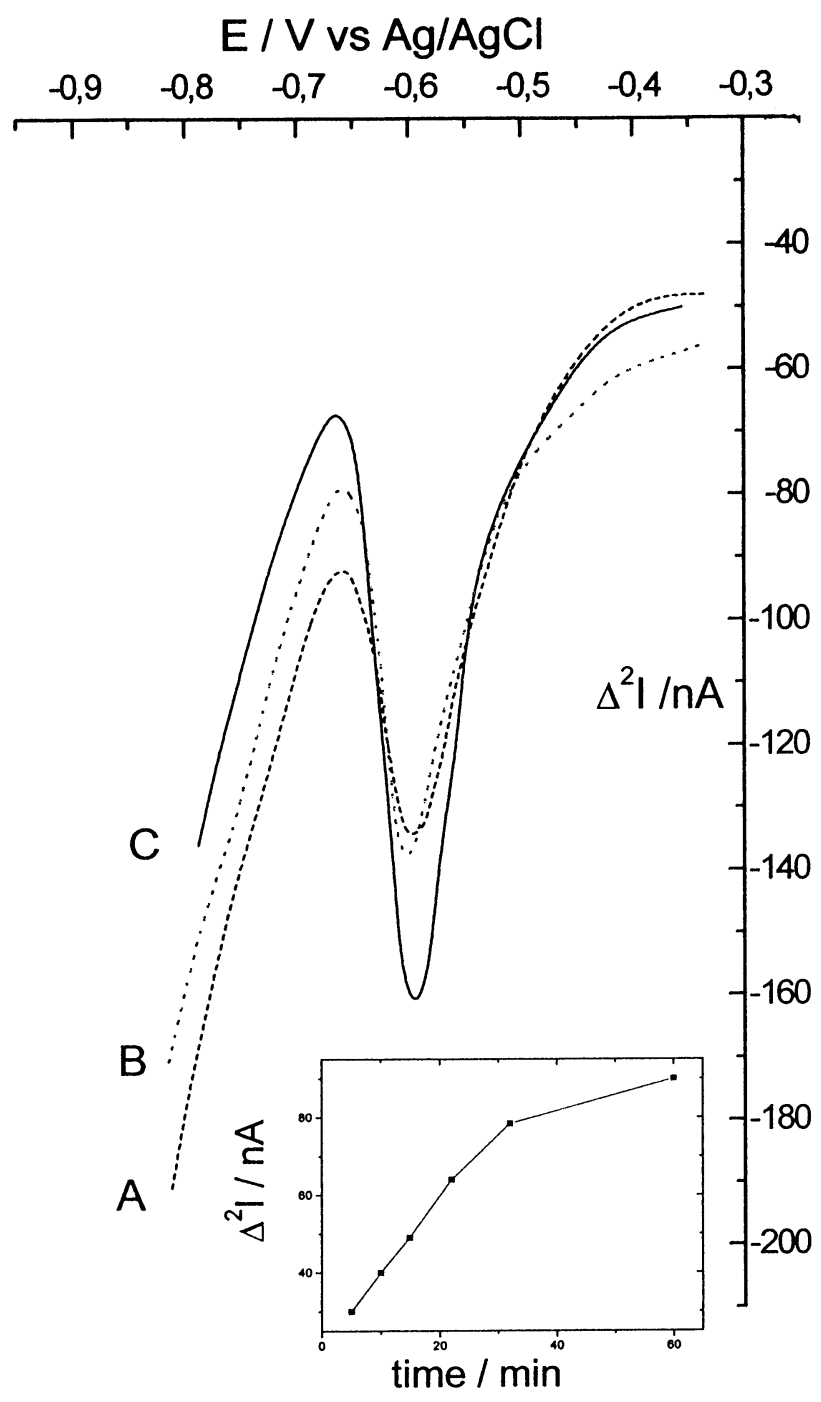

Fig. 2. Reduction scans recorded in MSW-DD at a NCE in $10 \mathrm{nM}$ $\mathrm{Eu}^{3+}, 0.1 \mathrm{M} \mathrm{NaCl}, \mathrm{pH} 4.0$, for different incorporation times: (A) 5 min, (B) $20 \mathrm{~min}$ and (C) $60 \mathrm{~min}$. Other experimental conditions: $\Delta E_{\mathrm{s}}=5 \mathrm{mV}, \Delta E_{\mathrm{amp}}=50 \mathrm{mV}, N=10$, integration time $20 \mathrm{~ms}$, initial potential $E_{\text {in }}=-0.350 \mathrm{~V}$. Insert: dependence of peak height (peak to peak amplitude in current units) on the incorporation time.

The chronoamperometric curves were recorded with a two channel oscilloscope Nicolet model 3091 (Nicolet Instrument Corporation, Madison, Wisconsin, USA).

The rotating disk electrode unit was the EG\&G Princeton Applied Research (PARC) model 636 electrode rotator.

For inductively coupled-plasma mass spectrometry (ICP-MS) measurements an Element instrument (double-focusing ICP-MS, Finnigan MAT, Bremen, Germany) was used. The instrument has predefined resolution settings of 300 (low-resolution mode, LRM), 3000 (medium-resolution mode, MRM) and 7500 (highresolution mode, HRM) $m / \Delta m$ ( $10 \%$ valley definition), which allow the signal of the analyte to be separated from those of most of the interferences.

\section{Results and discussion}

\section{1. $M S W-D D$ voltammogram}

As shown in Fig. 2, when a NCE is dipped in a solution containing $10 \mathrm{nM} \mathrm{Eu}^{3+}$, the progressive increase of the MSW-DD signal with dipping time is observed. As shown in the insert, signals start to reach an asymptotically steady value at times longer than 30 min. Note that under these experimental conditions no signal is obtained in the explored potential region by using MSWV at an unmodified glassy carbon electrode or DPV at a NCE. The morphology of the DD response can be roughly explained as follows: the positive going and negative going parts of the peak (with respect to what would be the baseline) are approximately the respective signal responses to each part (positive and negative) of the sequence of pulses applied to the electrode; i.e. the pulses $\Delta E_{\mathrm{amp}}+$ (as indicated in Fig. 1 ), if they were the only overimposed perturbation on a given $E_{\mathrm{s}}$, would produce a MSWV signal corresponding to the positive going peak of Fig. 1 (or Fig. 2 as well); symmetrically the $\Delta E_{\mathrm{amp}}-$ alone would give rise to the opposite (negative going) peak. The overall response in Figs. 1 and 2 is the sum of these components.

In practice, each point of the response signal (i.e. for one value of $E_{\mathrm{s}}$ ) is built from the integrals of the transient currents taken as indicated in Figs. 4 and 5 (see below). The integrals are added sequentially, with a convenient sign for accumulating the passing charges, during the $N$ pulses $\Delta E_{\text {amp }}+$ (positive part of the charge response) and during the $N$ subsequent pulses $\Delta E_{\text {amp }}-$ (negative contribution). This construction is then a linear combination of elements (faradic charges) which are individually proportional to the bulk concentration of the analyte.

For this reason the easy to measure peak to peak amplitude in the DD mode is proportional to the concentration of the electroactive species when, of course, only simple electron transfer is involved, as for other electroanalytical pulsed methods.

It should be noted that the determination of the baseline in Fig. 1 is obvious, while in Fig. 2 it is much more difficult to define (unless a blank experiment is performed); however, quantitative measurement of the concentrations only requires the peak to peak amplitude, provided that between a series of experiments this baseline stays nearly unmodified.

The twin opposite peaks are located at potential values which are symmetrical with respect to $E_{1 / 2}$. This is confirmed by the agreement between the $E_{1 / 2}$ value calculated from the MSW-DD curves as $E_{1 / 2}=\left(E_{\mathrm{pf}}+\right.$ $\left.E_{\mathrm{pb}}\right) / 2$ (which gives $-0.660 \mathrm{~V}$ ) and the $E_{1 / 2}$ values obtained by cyclic voltammetry at $\mathrm{NCE}$ in solutions containing higher europium concentrations [17]. 
The peak to peak width measured experimentally $\left(\Delta E_{\mathrm{w}}\right)$ (see Table 1) results in higher than $\Delta E_{\mathrm{amp}}$ values. This parameter in the MSW-DD pattern depends, in fact, on the number of electrons exchanged, $n$, and on the reversibility of the process. In the case of europium, the evidence that values are higher than $\Delta E_{\text {amp }}$ agrees with the quasi-reversible behaviour reported for the $\mathrm{Eu}^{3+/ 2+}$ couple on glassy carbon electrodes $[25,26]$. As shown in Fig. 3 and Table 1, the peak heights measured as the peak to peak amplitude on the current axis, increase linearly with $\Delta E_{\mathrm{amp}}$. This agrees with previous literature findings obtained by applying MSWV in the normal mode at a HMDE for copper determination [27], and by applying MSWV in DD mode at a NCE for methylmercury determination [15]. Concerning the asymmetry in amplitude of the opposite peaks which appears in Fig. 3, it should be noted that even in the ideal case (reversible reactions under semi-infinite planar diffusion) this asymmetric shape can be observed. In the present situation, which is far from the ideal case, the asymmetry could be ascribed to several possible causes: difference in the diffusion coefficients of the

Table 1

Effect of $\Delta E_{\mathrm{amp}}$ on the peak to peak width $\left(\Delta E_{\mathrm{w}}\right)$ and on the peak to peak height $\left(\Delta^{2} I\right)$ for MSW-DD of $\mathrm{Eu}^{3+}$ at NCE; other experimental conditions as in Fig. 3

\begin{tabular}{lcc}
\hline$\Delta E_{\mathrm{amp}} / \mathrm{mV}$ & $\Delta E_{\mathrm{w}} / \mathrm{mV}$ & $\Delta^{2} I / \mathrm{nA}$ \\
\hline 25 & 76 & 47.7 \\
50 & 100 & 126.4 \\
75 & 110 & 181.2 \\
\hline
\end{tabular}

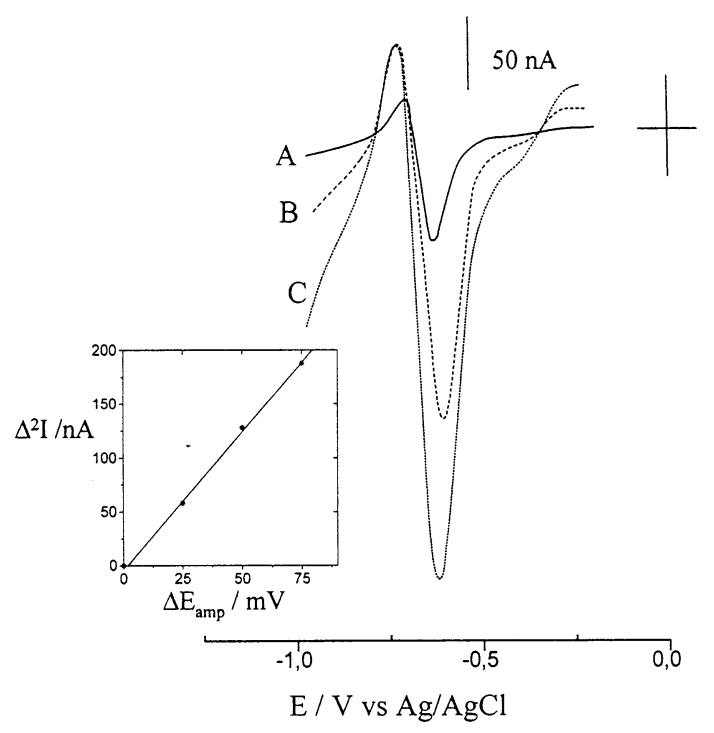

Fig. 3. MSW-DD scans recorded at a NCE equilibrated in $50 \mathrm{nM}$ $\mathrm{Eu}^{3+}, 0.1 \mathrm{M} \mathrm{NaNO}_{3} . \Delta E$ values: (A) 25 , (B) 50 and (C) $75 \mathrm{mV}$. Other experimental parameters: $\Delta E_{\mathrm{s}}=5 \mathrm{mV}, N=10$, integration time $20 \mathrm{~ms} ; E_{\text {in }}=-0.250 \mathrm{~V}$. Insert: dependence of peak height (peak to peak amplitude) on $\Delta E_{\text {amp. }}$. reduced and oxidised species, differences in the residual capacitive currents, depletion effects in the reaction layer, low reversibility and differences in the values of the transfer coefficients.

Fig. 4 shows the chronoamperometric decays of the currents for $\mathrm{Eu}^{3+}$ incorporated into a NCE, when different $\Delta E_{\text {amp }}$ values are applied. The current displayed is recorded after a delay time $\left(\tau_{1}\right)$ of $5.5 \mathrm{~ms}$, which allows the charging current (broken line) to decay. The capacitive decay is picked up on a test point of the instrument where shift and compensation are not total; the zero current is not shown on these diagrams. Note that in the instrument, the capacitive contribution is separated from the faradic content of the transient using a commutation in the sensitivity of the current measurement; a reduced sensitivity range is, in fact, applied during the short initial period $\left(\tau_{1}\right)$ to allow the capacitive charge to pass through without saturating the circuits, after that a high sensitivity is activated and the low faradic current component can be measured. This double scaling is clearly visible in Fig. 4 (and Fig. 5, see below).

Faradic currents decays give linear $I$ versus $t^{-1 / 2}$ plots, indicating that in the pulse time scale used (typically $\leq 100 \mathrm{~ms}$ ), charge transfer at the electrode|Nafion ${ }^{\circledR}$ interface is diffusion controlled [28]. Note that at the modified electrodes, when the pulse time, $t_{\mathrm{p}}$, is too long the diffusion layer can widen so much as to extend (theoretically) out of the thickness of the coating, $\phi$; this happens when $t_{\mathrm{p}} \geq \phi_{\mathrm{p}}^{2} / D_{\mathrm{app}}$, where $D_{\text {app }}$ is the apparent diffusion coefficient which determines the charge transfer process in the coating $[4,28]$. If this were the case, the current would not follow pure Cottrellian behaviour, but the transition from Cottrellian to thin-layer behaviour should be observed. Under our experimental conditions, considering that $\phi_{\mathrm{p}} \approx 2$ $\mu \mathrm{m}$ and $D_{\text {app }}\left(\mathrm{Eu}^{3+}\right)=1.2 \times 10^{-8} \mathrm{~cm}^{2} \mathrm{~s}^{-1}$ [17], the transition between semi-infinite linear diffusion and thin layer-like behaviour is expected to happen only for time pulses larger than $3.3 \mathrm{~s}$.

As shown in Fig. 4, faradic chronoamperometric currents increase with the pulse amplitude. Since the signal being recorded in MSW-DD is really the charge sampled after $\tau_{1}$, it is clear that the increase in $\Delta E_{\text {amp }}$ reflects an increase in signals. On the other hand, the MSW-DD patterns in Fig. 3 show that the increase of $\Delta E_{\text {amp }}$ produces more sloping baselines. The insert in Fig. 3 shows that a compromise can be found in order to optimise the sensitivity with a flat baseline and small peak to peak width; in the case of nanomolar levels of europium, we considered that $\Delta E_{\text {amp }}=50 \mathrm{mV}$ gives a satisfactory response, with high $\Delta^{2} I$ and flat enough background signals.

Fig. 5 shows the effect of the pre-sampling time on the signals. $\tau_{1}$ should be long enough to allow the decay of the charging current (full line), but not so long as to 


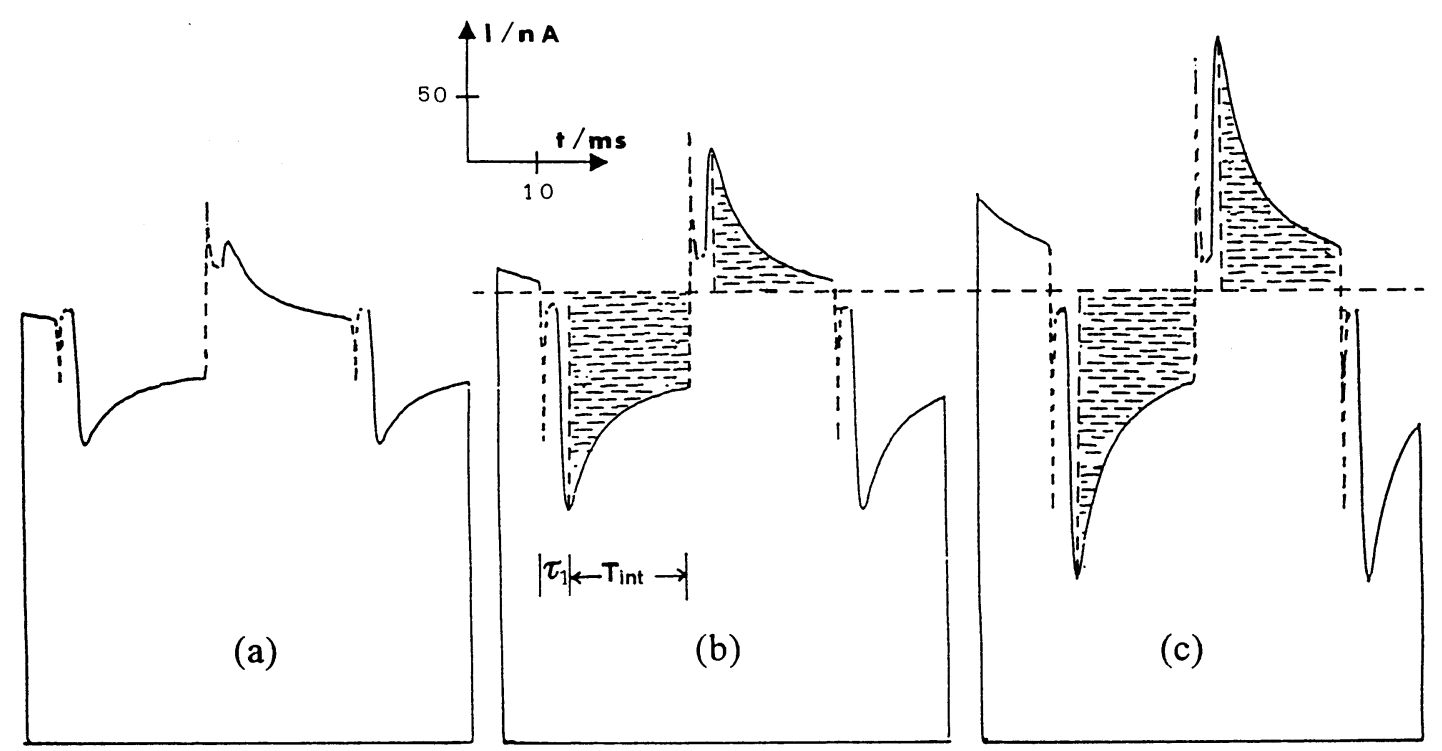

Fig. 4. Chronoamperometric decays of currents recorded by an oscilloscope during a MSW-DD for different $\Delta E_{\text {amp }}$ : (a) $25 \mathrm{mV}$, (b) $50 \mathrm{mV}$, (c) $75 \mathrm{mV}$. Other experimental conditions as in Fig. 3. Note that the sensitivity on the $Y$ axes during the pre-pulse time (charging current decay) is about 100 times less than the value used for recording the faradic current decay. Localisation of a pair of integrals is represented on the second part of the graph.

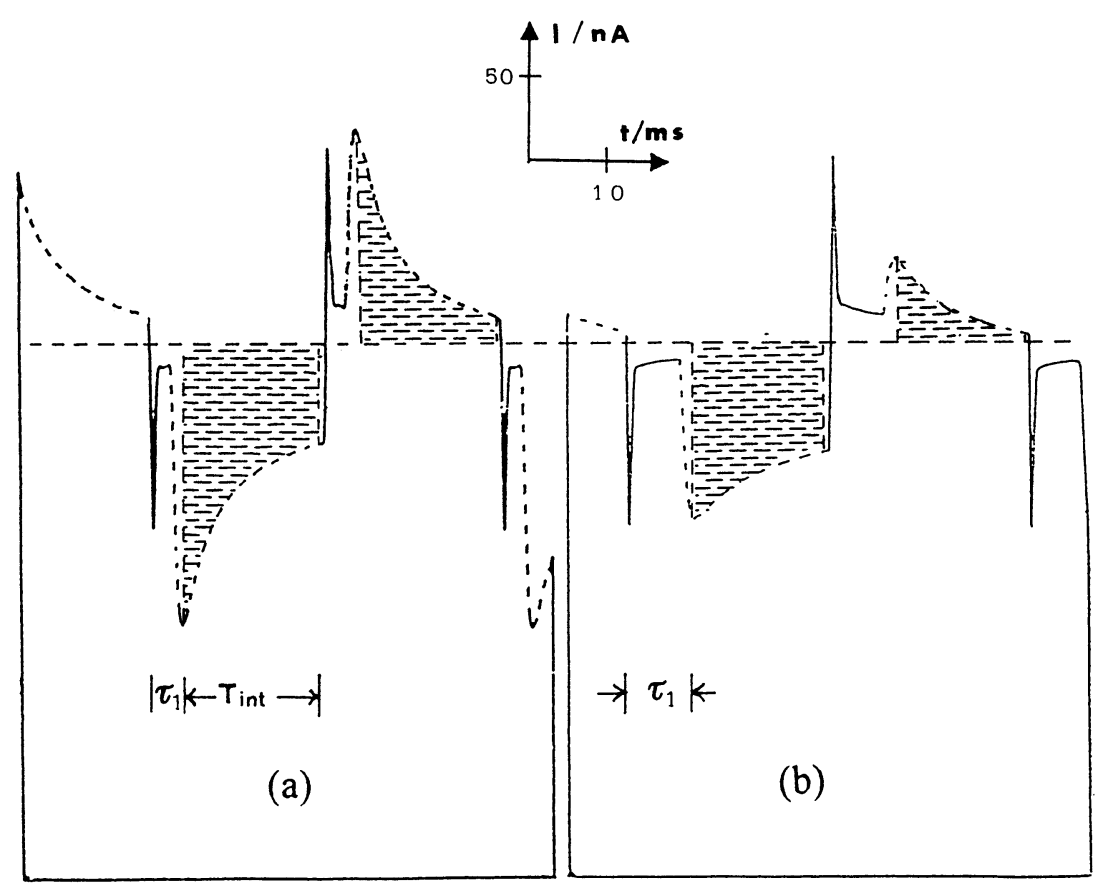

Fig. 5. Chronoamperometric decays of currents recorded by an oscilloscope during MSW-DD scans carried out using two different pre-sampling times: (a) $5.5 \mathrm{~ms}$, (b) $10.0 \mathrm{~ms}$. Other experimental conditions as in Fig. 3.

depress the faradic component of the signals (broken line). For $\mathrm{Eu}^{3+}$ determinations at $\mathrm{NCE}$, we found 5.5 $\mathrm{ms}$ to be the best value for this parameter.

In principle, the effect of increasing the number of pulses, $N$, should be to increase the voltammetric signal. However, by an instrumental procedure (see Eq. (1)), the signal is normalised by the number of pulses superimposed on each step of the staircase; as a result the peak to peak height (faradic current) does not increase, but the noise (capacitive and background currents) is minimised. As a consequence, the signal to noise ratio is increased and a better resolution of the voltammogram is reached. Fig. 6 shows the voltammetric response at a $\mathrm{NCE}$ in solution containing only the supporting electrolyte for different $N$ values. The effect of the number of pulses in decreasing the slope of the 
baseline is evident; however, increasing $N$ increases the total scan time. Statistical evaluation of sets of scans in blank solutions at different $N$ values is presented in Table 2. These data reveal that the experimental background noise $\left(\sigma_{\mathrm{b}}\right)$, given as the standard deviation of 15 independent background current measurements, decreases with increasing $N$; on the other hand, the scan time increases with the same parameter. Again a compromise will drive the choice, which in our case, resulted in a $N$ value of 15 (when the integration time applied during each pulse is set at $20 \mathrm{~ms}$ ).

\subsection{Optimisation of experimental conditions and analytical parameters}

In order to shorten the duration of the preconcentration step, a rotating NCE was applied; in fact the enhancement of the mass transfer rate obtained by

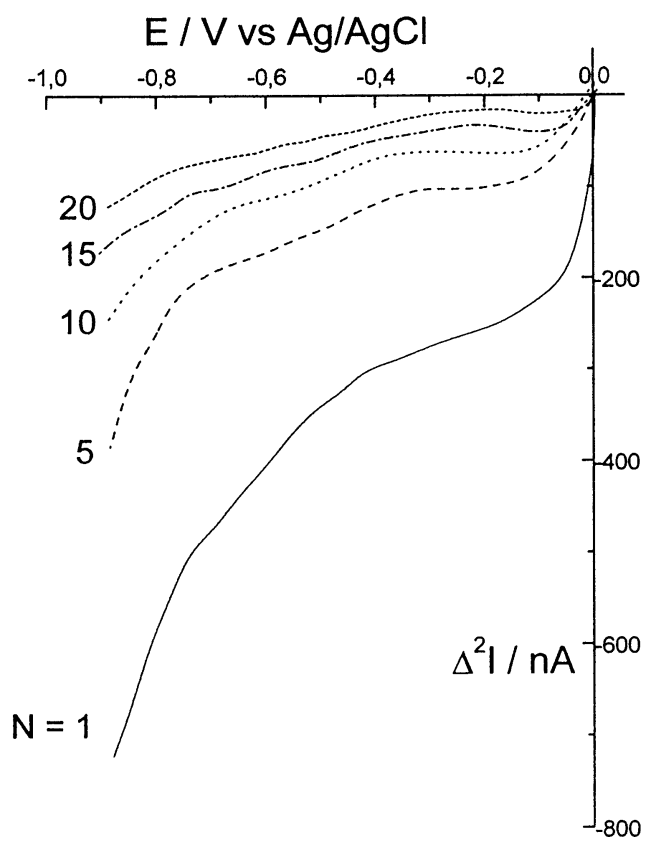

Fig. 6. MSWV voltammetric responses at a NCE in blank solution $(0.1 \mathrm{M} \mathrm{NaCl})$ for different $N$ values. Other experimental parameters: $\Delta E_{\mathrm{s}}=5 \mathrm{mV}, \Delta E_{\mathrm{amp}}=25 \mathrm{mV}$, integration time $20 \mathrm{~ms}, E_{\mathrm{in}}=0 \mathrm{~V}$.

Table 2

Statistical evaluation of series of 15 scans at different $N$ values, in MSW-DD at a NCE dipped in $0.1 \mathrm{M} \mathrm{NaCl}$ solution (blank); other experimental parameters: $\Delta E_{\mathrm{s}}=5 \mathrm{mV}, \Delta E_{\mathrm{amp}}=25 \mathrm{mV}$, integration time $20 \mathrm{~ms}$

\begin{tabular}{rcrc}
\hline$N$ & $I_{\text {average }} / \mathrm{nA}$ & $\sigma_{\mathrm{b}} / \mathrm{nA}^{\mathrm{a}}$ & Scan time $/ \mathrm{s}$ \\
\hline 1 & 419 & 41.10 & 20 \\
5 & 189 & 5.96 & 94 \\
10 & 124 & 6.07 & 188 \\
20 & 73.3 & 6.32 & 373
\end{tabular}

\footnotetext{
${ }^{\mathrm{a}} \sigma_{\mathrm{b}}$ : standard deviation of 15 independent background measurements.
}

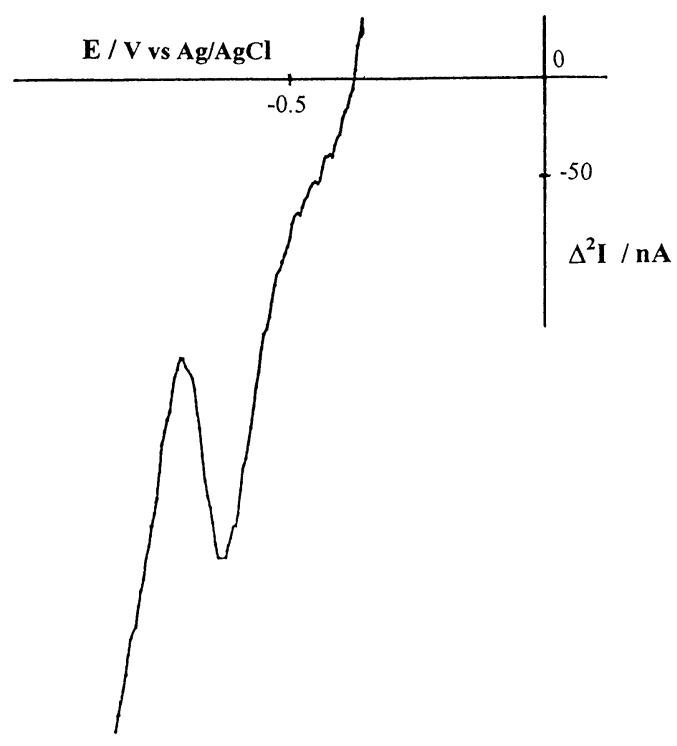

Fig. 7. MSW-DD curves recorded at a NCE equilibrated in $0.3 \mathrm{nM}$ $\mathrm{Eu}^{3+}, 0.1 \mathrm{M} \mathrm{NH}_{4} \mathrm{Cl}$. Other experimental parameters: $\Delta E_{\mathrm{s}}=5 \mathrm{mV}$, $\Delta E_{\text {amp }}=50 \mathrm{mV}, N=10$, integration time $20 \mathrm{~ms}, E_{\text {in }}=-0.250 \mathrm{~V}$.

operating under mixed convective-diffusive conditions should accelerate the achievement of the ion-exchange equilibrium. On the basis of previous studies [18], the ion-exchange preconcentration step was carried out at $2000 \mathrm{rpm}$. The time required to reach ion-exchange equilibrium conditions depends on the analyte concentration and this time increases when lowering the analyte concentration [18]. From a qualitative point of view this can be explained by the fact that, under open circuit conditions, the rate of mass transport of the analyte from the solution to the polymer is driven by the concentration gradient existing between the bulk solution and the solution|polymer interface (and generated by the ion-exchange incorporation of the analyte); the lower is the bulk concentration, the smaller is this gradient. In the concentration range explored more deeply in the present work, i.e. in the $\mathrm{nM}$ range, a preconcentration time of $20 \mathrm{~min}$ at $2000 \mathrm{rpm}$ is long enough to produce a steady signal.

Fig. 7 shows the MSW pattern recorded at subnanomolar europium concentration levels (namely 0.3 $\mathrm{nM}$ for Fig. 7); in this case the supporting electrolyte is $0.1 \mathrm{M} \mathrm{NH}_{4} \mathrm{Cl}$. Signals increase linearly with the analyte concentration so that quantification of the concentrations can also be carried out at such low concentration levels. Table 3 compares the analytical parameters obtained using supporting electrolytes of different nature and concentration. The higher signals obtained using $\mathrm{NH}_{4}^{+}$agree with the $\mathrm{pH}$ buffering capability of this cation which improves the reversibility of the reduction of rare earth cations at electrodes coated with Nafion ${ }^{\circledR}$ [17]. The increase of signal with decreasing concentration of supporting electrolyte is explained by the ion-exchange nature of the preconcentration process itself; the 
lower is the supporting electrolyte concentration, the less it competes with the analytes for the ion-exchange sites of Nafion ${ }^{\circledR}$. The detection limit achieved using $10^{-3} \mathrm{M} \mathrm{NH} \mathrm{NH}_{4} \mathrm{Cl}$ supporting electrolyte is remarkably low.

On the basis of relevant $E_{1 / 2}$ values and on the preconcentration capabilities of $\mathrm{Nafion}^{\circledR}$ coatings, a possible interference with the europium determination in water solutions could be $\mathrm{Pb}^{2+}$. It was shown that this cation is preconcentrated in $\mathrm{Nafion}^{\circledR}$ and gives voltammetric signals centred around an $E_{1 / 2}$ value not too far from the $E_{1 / 2}$ of the $\mathrm{Eu}^{3+/ 2+}$ couple [15]. For this reason the influence of the presence of increasing amounts of lead on the europium MSW-DD responses was investigated. Preliminary tests carried out in $\mathrm{NH}_{4} \mathrm{Cl}$ supporting electrolyte and $\mathrm{Eu}^{3+}$ and $\mathrm{Pb}^{2+}$ solution concentrations in the nanomolar range showed that under these experimental conditions just one unresolved MSW-DD twin opposite peak system is observed. Under these conditions, signals for the analyte $\left(\mathrm{Eu}^{3+}\right)$ and the interference $\left(\mathrm{Pb}^{2+}\right)$ are unresolved. This situation changes dramatically when acetate is

Table 3

Analytical parameters: background noise $\left(\sigma_{\mathrm{b}}\right)$, sensitivity $(m)$ and detection limits (DL) obtained for $\mathrm{Eu}^{3+}$ determinations in MSW-DD at a NCE using supporting electrolytes of different nature and concentration; other experimental conditions: $\Delta E_{\mathrm{s}}=5 \mathrm{mV}, \Delta E_{\mathrm{amp}}=$ $50 \mathrm{mV}, N=15$, integration time $20 \mathrm{~ms}$

\begin{tabular}{lccl}
\hline Supporting electrolyte & $\sigma_{\mathrm{b}} / \mathrm{nA}$ & $m / \mathrm{nA} \mathrm{nM}^{-1}$ & $\mathrm{DL} / \mathrm{nM}$ \\
\hline $0.1 \mathrm{M} \mathrm{NaCl}$ & 6.25 & 59 & 0.30 \\
$0.1 \mathrm{M} \mathrm{NH}_{4} \mathrm{Cl}$ & 4.10 & 123 & 0.10 \\
$0.001 \mathrm{M} \mathrm{NH}_{4} \mathrm{Cl}$ & 6.32 & 1800 & 0.01 \\
\hline
\end{tabular}

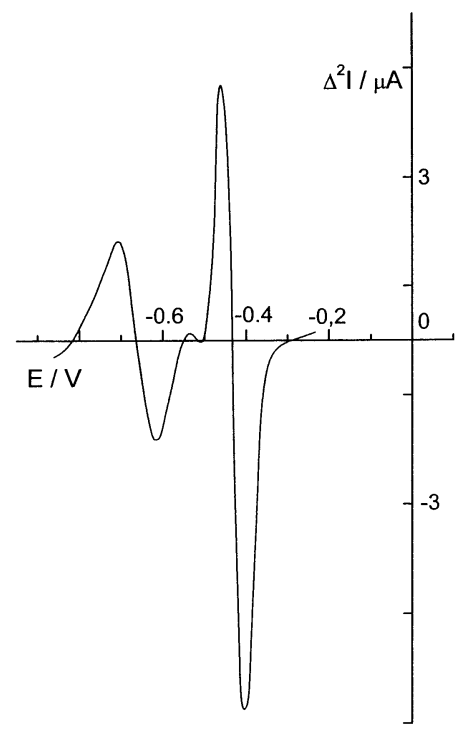

Fig. 8. MSW-DD voltammograms recorded at a NCE in $0.1 \mathrm{M} \mathrm{NaCl}$, $5 \mathrm{nM} \mathrm{Eu}^{3+}, 200 \mathrm{nM} \mathrm{Pb}^{2+}, 0.1 \mathrm{M} \mathrm{CH}_{3} \mathrm{COONa}, \mathrm{pH}$ 4.0. Other experimental conditions as in Fig. 7. added to the solution. Fig. 8 shows that under the latter experimental conditions (i.e. in the presence of acetate) two separated MSW-DD pairs of twin opposite peaks are observed. Increasing the amount of lead causes an increase of the system centred at about $-0.450 \mathrm{~V}$, which therefore was attributed to the reduction of interfering lead. The increase of the concentration of lead really does not influence $\Delta^{2} I$ values relevant to the $\mathrm{Eu}^{3+/ 2+}$ system (centred at $-0.650 \mathrm{~V}$ ) which increase linearly with the europium solution concentration, at least until the level of excess $\mathrm{Pb}^{2+}$ is less than 50 times the $\mathrm{Eu}^{3+}$ concentration. This evidence suggests that for $\mathrm{Eu}^{3+}$ determination in samples containing significant amounts of $\mathrm{Pb}^{2+}$, the use of acetate electrolyte is recommended; the different complexation of the two cations by acetate [29] is reflected in different shifts in relevant $E_{1 / 2}$ values, so that two separated peak systems are observed. It is worth noting that the peak to peak width $\left(\Delta E_{\mathrm{w}}\right)$ of the europium system is approximately double that of the lead system. This agrees with the above mentioned dependence of peak to peak potential width on the number of electrons exchanged, which is two for lead(II) reduction and one for europium(III) reduction.

\subsection{Application to real samples}

The suitability of the proposed method to the analysis of real samples was checked by determining the europium(III) concentration in the water from a pool type, light water moderated and graphite reflected research nuclear reactor. The pool water quality is excellent, the $\mathrm{pH}$ is kept between 5.5 and 6.5, the conductivity is around $2 \mu \mathrm{S} \mathrm{cm}{ }^{-1}$ and chlorides are less than $0.5 \mathrm{ppm}$. Despite these excellent water characteristics, pitting corrosion can give rise to the presence of trace metals in this water. Among these, the presence of europium is of interest since it can be indicative of problems of corrosion in the spent fuel elements deposited in the pool [24].

The procedure used for the analysis of the MSWDD-IEV of the pool water is summarised as follows.

1. The water sample was acidified with $\mathrm{HCl}$ Suprapur to $\mathrm{pH} 4.0$, bubbled with nitrogen in order to eliminate carbonate which can complex the $\mathrm{Eu}$ (III) ion [21], and then spiked with $\mathrm{NH}_{4} \mathrm{Cl}$ to give a final supporting electrolyte concentration of $10^{-3} \mathrm{M}$.

2. The ion-exchange preconcentration was carried out for $15 \mathrm{~min}$ in a stirred solution (400 rpm).

3. The NCE was conditioned by five potential scans from 0 to $-0.900 \mathrm{~V}$ using $\Delta E_{\mathrm{s}}=10 \mathrm{mV}, N=1$, $\Delta E_{\text {amp }}=25 \mathrm{mV}$.

4. The measurement scan was carried out starting from $-0.350 \mathrm{~V}$ to $-0.800 \mathrm{~V}$ using the following MSWDD parameters: $\Delta E_{\mathrm{s}}=5 \mathrm{mV}, N=15, \Delta E_{\mathrm{amp}}=50$ $\mathrm{mV}$. 


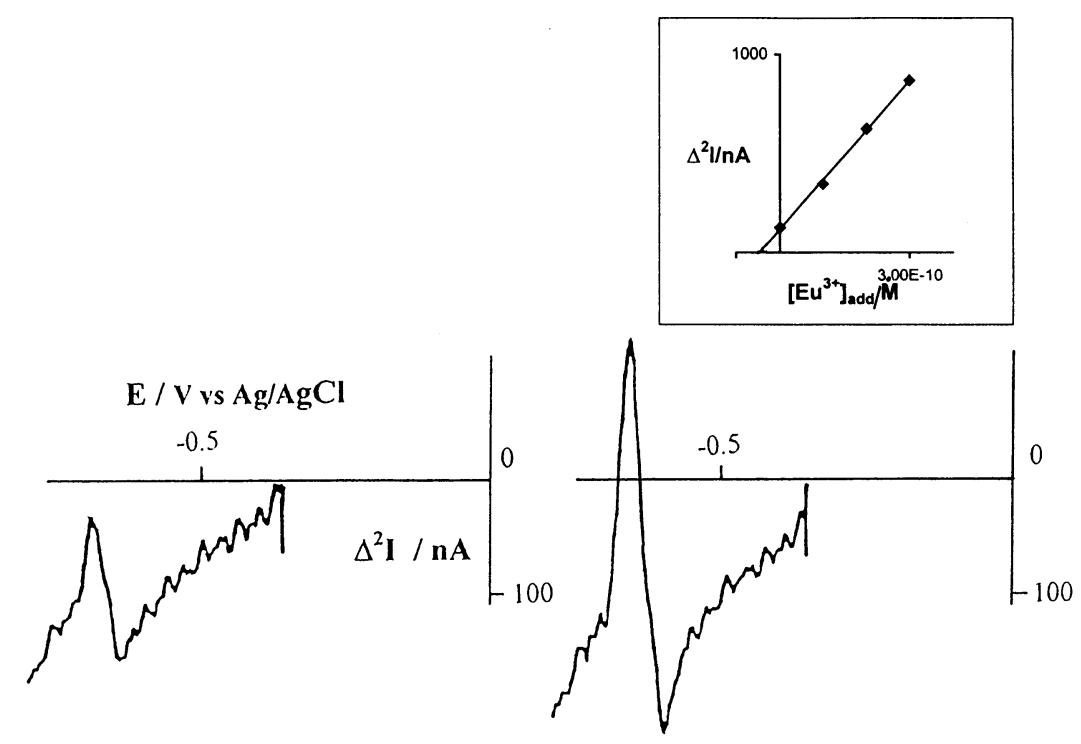

Fig. 9. MSW-DD voltammogram recorded at a NCE in a water sample from the cooling system of a nuclear reactor unspiked (left) and spiked (right) with $0.1 \mathrm{nM} \mathrm{Eu}^{3+}$. In both cases the sample contained added $\mathrm{NH}_{4} \mathrm{Cl}+\mathrm{HCl}$ (final concentrations $10^{-3} \mathrm{M}$ and $10^{-4} \mathrm{M}$, respectively). Other experimental parameters: $\Delta E_{\mathrm{s}}=5 \mathrm{mV}, \Delta E_{\mathrm{amp}}=50 \mathrm{mV}, N=15$, integration time $20 \mathrm{~ms}, E_{\mathrm{in}}=-0.350 \mathrm{~V}$, ion-exchange equilibration time 15 min. Insert: relevant standard additions.

The concentration of Eu(III) was quantified by standard additions. Typical DD-voltammograms recorded in the IEA-R1 water sample before (left) and after spiking (right) with the europium standard solution are shown in Fig. 9; the insert in the figure presents the quantification of the analyte by standard additions. No interference from $\mathrm{Pb}^{2+}$ was found in these samples. The europium concentration in the sample is $(3.4 \pm$ $0.9) \times 10^{-11} \mathrm{M}$ (average $\pm \sigma_{n-1}$, with $n=3$ ) .

As a comparison method, the concentration of europium in the same sample was analysed via ICP-MS spectrometry. The amount of europium present was determined with a calibration plot after subtracting the blank from the signal obtained for ${ }^{153} \mathrm{Eu}$, and considering the contribution from the formation of barium oxides. These are the main spectral interferences which hamper accurate europium ICP-MS determination; in the samples analysed in this work (which contain $1 \times$ $10^{-8} \mathrm{M} \mathrm{Ba}^{2+}$ ) the role of such interference cannot be neglected. After this correction, the amount of europium determined via ICP-MS was $(2.2 \pm 0.4) \times 10^{-11}$ M. Note that blank Eu concentrations was $1 \times 10^{-13}$ $M$ (determined via ICP-MS). The good agreement between MSW-DD-IEV data and ICP-MS data confirms the reliability and the high sensitivity of the MSW method.

\section{Conclusions}

The detailed analysis of the experimental parameters which determine voltammetric responses obtained by MSW-DD at Nafion ${ }^{\circledR}$ coated electrodes allowed opti- misation of the ion-exchange voltammetric determination of europium(III) at subnanomolar concentration levels. The method developed here has been applied for ultratrace europium determinations in real samples. The procedure used in order to optimise experimental parameters of the MSW-DD technique, can in principle, be extended to a variety of analytical challenges involving the ultratrace electroanalysis of electroactive ions preconcentrated at electrodes modified with ion-exchange coatings.

\section{Acknowledgements}

Financial support from MURST (Rome) and CRUI (Rome) is gratefully acknowledged. The authors thank IPEN-CNEN/SP Brazil for the nuclear reactor water sample and Dr C. Barbante (University of Venice) for kindly and competently performing the ICP-MS measurements.

\section{References}

[1] N. Oyama, F.C. Anson, J. Electrochem. Soc. 127 (1980) 247. [2] I. Rubinstein, A.J. Bard, J. Am. Chem. Soc. 102 (1980) 6641.

[3] M.W. Espenscheid, A.R. Ghatak-Roy, R.B. Moore III, R.M. Penner, M.N. Szentirmay, C.R. Martin, J. Chem. Soc., Faraday Trans. I 82 (1986) 1051.

[4] P. Ugo, L.M. Moretto, Electroanalysis 7 (1995) 1105.

[5] P. Ugo, L.M. Moretto, S. Bellomi, V.P. Menon, C.R. Martin, Anal. Chem. 68 (1996) 4160.

[6] N. Fatouros, J.P. Simonin, J. Chevalet, R.M. Reeves, J. Electroanal. Chem. 213 (1986) 1. 
[7] D. Krulic, N. Fatouros, J. Chevalet, J. Electroanal. Chem. 287 (1990) 215

[8] G.C. Barker, A.W. Gardner, AERE Harwell, UK, Reports C/G 2297 (1958) G.

[9] G.C. Barker, A.W. Gardner, Analyst 77 (1952) 685.

[10] J. Chevalet, G.Y. Champagne, L. Gastonguay, R. Lacasse, M. Ladouceur, N. Fatouros, D. Krulic, J. Chim. Phys. 93 (1996) 804.

[11] G.Y. Champagne, J. Chevalet, International Patent pending, No. PCT/CA97/00593, 20 August 1997.

[12] R. Lacasse, G.Y. Champagne, L. Gastongay, M. Ladouceur, J. Chevalet, Report HydroQuebec, IREQ 97-207, December 1997.

[13] R. Lacasse, L. Gastongay, M. Ladouceur, J. Chevalet, Report HydroQuebec, IREQ 97-277, December 1997.

[14] R. Lacasse, G.Y. Champagne, L. Gastongay, M. Ladouceur, J. Chevalet, L.M. Moretto, Report HydroQuebec, IREQ 97-269 C, December 1997.

[15] L.M. Moretto, P. Ugo, R. Lacasse, G.Y. Champagne, J. Chevalet, J. Electroanal. Chem. 467 (1999) 184.

[16] M. Leermakers, P. Lansens, W. Baeyens, Fresenius J. Anal. Chem. 336 (1990) 655.

[17] P. Ugo, B. Ballarin, S. Daniele, G.A. Mazzocchin, J. Electroanal. Chem. 291 (1990) 187.
[18] P. Ugo, B. Ballarin, S. Daniele, G.A. Mazzocchin, Anal. Chim. Acta 244 (1991) 29.

[19] L.M. Moretto, B. Brunetti, J. Chevalet, P. Ugo, Electrochem. Commun. 2 (2000) 175.

[20] R.G. Bautista, N. Jackson (Eds.), Rare Earths, Resources, Science, Technology and Applications, TMS, USA, 1991.

[21] J.-C.G. Bünzli, G.R. Choppin (Eds.), Lanthanide Probes in Life, Chemicals and Earth Sciences, Elsevier, Amsterdam, 1989.

[22] C. Moulin, J. Wei, P. Van Iseghem, I. Laszak, G. Plancque, V. Moulin, Anal. Chim. Acta 396 (1999) 253.

[23] K.A. Mauritz, C.J. Hora, A. Hopfinger, J. Polym. Prep. Am. Chem. Soc. Div. Polym. Chem. 19 (1978) 324.

[24] J.A. Perrotta, L.A.A. Terremoto, C.A. Zeituni, Ann. Nucl. Energy 25 (1998) 237.

[25] R. Lange, K. Doblhofer, W. Storck, Electrochim. Acta 33 (1988) 385.

[26] C.A. McDermott, K.R. Knetern, R.L. McCreery, J. Electrochem. Soc. 140 (1993) 2593.

[27] D. Krulic, PhD Thesis, Université Paris 6, 1989.

[28] N. Oyama, A. Yamaguchi, Y. Nishiki, K. Tokuda, H. Matsuda, F.C. Anson, J. Electroanal. Chem. 139 (1982) 371.

[29] R.M. Smith, A.E. Martell, Critical Stability Constants, vol. 3, Plenum, New York, 1989. 